\title{
Wearable-Based Mobile Health App in Gastric Cancer Patients for Postoperative Physical Activity Monitoring: Focus Group Study
}

Jin-Ming $\mathrm{Wu}^{1,2}, \mathrm{MD}, \mathrm{PhD}$; Te-Wei Ho ${ }^{1 *}, \mathrm{PhD}$; Yao-Ting Chang ${ }^{3}$, MS; ChungChieh $\mathrm{Hsu}^{3}$, MS; Chia Jui Tsai ${ }^{3}$, MS; Feipei Lai ${ }^{3}, \mathrm{PhD} ;$ Ming-Tsan $\operatorname{Lin}^{1,2^{*}}, \mathrm{MD}, \mathrm{PhD}$

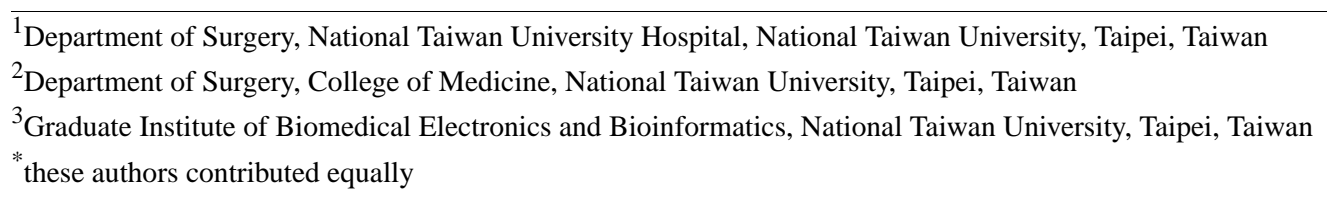

Corresponding Author:

Ming-Tsan Lin, MD, PhD

Department of Surgery

National Taiwan University Hospital

National Taiwan University

No.7 Chung Shan South Road

Taipei,

Taiwan

Phone: 886223123456

Email: $\underline{\text { linmt@ntu.edu.tw }}$

\section{Abstract}

Background: Surgical cancer patients often have deteriorated physical activity (PA), which in turn, contributes to poor outcomes and early recurrence of cancer. Mobile health (mHealth) platforms are progressively used for monitoring clinical conditions in medical subjects. Despite prevalent enthusiasm for the use of mHealth, limited studies have applied these platforms to surgical patients who are in much need of care because of acutely significant loss of physical function during the postoperative period.

Objective: The aim of our study was to determine the feasibility and clinical value of using 1 wearable device connected with the mHealth platform to record PA among patients with gastric cancer (GC) who had undergone gastrectomy.

Methods: We enrolled surgical GC patients during their inpatient stay and trained them to use the app and wearable device, enabling them to automatically monitor their walking steps. The patients continued to transmit data until postoperative day 28 . The primary aim of this study was to validate the feasibility of this system, which was defined as the proportion of participants using each element of the system (wearing the device and uploading step counts) for at least 70\% of the 28-day study. "Definitely feasible," "possibly feasible," and "not feasible" were defined as $\geq 70 \%, 50 \%-69 \%$, and $<50 \%$ of participants meeting the criteria, respectively. Moreover, the secondary aim was to evaluate the clinical value of measuring walking steps by examining whether they were associated with early discharge (length of hospital stay $<9$ days).

Results: We enrolled $43 \mathrm{GC}$ inpatients for the analysis. The weekly submission rate at the first, second, third, and fourth week was $100 \%, 93 \%, 91 \%$, and $86 \%$, respectively. The overall daily submission rate was $95.5 \%$ (1150 days, with 43 subjects submitting data for 28 days). These data showed that this system met the definition of "definitely feasible." Of the 54 missed transmission days, 6 occurred in week 2, 12 occurred in week 3, and 36 occurred in week 4 . The primary reason for not sending data was that patients or caregivers forgot to charge the wearable devices ( $>90 \%)$. Furthermore, we used a multivariable-adjusted model to predict early discharge, which demonstrated that every 1000-step increment of walking on postoperative day 5 was associated with early discharge (odds ratio $2.72,95 \%$ CI $1.17-6.32 ; P=.02$ ).

Conclusions: Incorporating the use of mobile phone apps with wearable devices to record PA in patients of postoperative GC was feasible in patients undergoing gastrectomy in this study. With the support of the $m$ Health platform, this app offers seamless tracing of patients' recovery with a little extra burden and turns subjective PA into an objective, measurable parameter.

(JMIR Mhealth Uhealth 2019;7(4):e11989) doi: $\underline{10.2196 / 11989}$

\section{KEYWORDS}

telemedicine; exercise; perioperative care; gastrectomy; stomach neoplasms 


\section{Introduction}

\section{Background}

Physical activity (PA) is a well-established parameter to not only assess the general condition but also monitor the recovery of patients [1,2]. Regular PA can be protective against the risk of gastric and breast cancers $[3,4]$. Although the double-labeled water method is considered to be the gold standard for assessing total energy expenditure (to reflect PA), it is rarely used because it is expensive, equipment dependent, and time consuming $[5,6]$. Therefore, other modalities, including self-report questionnaires, self-report activity diaries, direct observation, and devices (accelerometers, pedometers, or armbands), have been implemented to measure PA [6].

Gastric cancer (GC) is the fourth leading cancer worldwide and the second leading cause of cancer-related mortality [7]. In Taiwan, nearly 3800 new cases of GC are reported each year in patients with a median age of 70 years. Complete surgical resection and endoscopic submucosal resection are the only curative therapies that provide better long-term survival. Nevertheless, gastrectomy-related stress and discomfort adversely affect PA and quality of life immediately postoperatively and last for up to 6 months [8], contributing to poor outcomes or early recurrence, particularly in cases with advanced-stage GC with obstruction of the gastrointestinal tract and malnutrition $[9,10]$. Furthermore, PA declines more markedly in patients who have undergone gastrectomy and are receiving postoperative chemotherapy or chemoradiation [11]. Moreover, patients with GC encounter significant functional impairments and decreased quality of life because of decreased PA and increased gastrointestinal symptoms [12]. Despite the deterioration in physical function, regular PA (to strengthen muscle power, which leads to improved physical function), proper nutritional intervention (to improve food intake, which results in weight gain), and mental support (to preserve self-esteem and maintain social activity) may help in restoring the patients' health status and improving quality of life [13].

Traditional perioperative care depends on medical professionals asking patients about the progression of their PA; however, these self-report measures are not only unreliable in aged adults with cognitive impairment [14] but also time consuming in processing the data [15]. For the purpose of clinical research, self-report questionnaires are the most common method for PA assessment, and they have the advantage of cost-effectiveness and ease of administration [6]. However, compared with using devices for recording PA, potential disadvantages of self-report questionnaires are that they may be less reliable in measuring light or moderate PA and may also be affected by external factors, such as social desirability, age, complexity of the questionnaire, and the participants' recall ability [16,17]. Furthermore, 4 key categories of aging barriers are associated with the use of mobile health (mHealth) in aged adults, including barriers in cognition, motivation, physical ability, and perception [18]. As GC typically comprises an aged population (median age $>65$ years) with the potential for developing cognitive or memory impairments, it is important to select an easy-to-follow PA device to use in clinical research for this population.
mHealth is a scalable and flexible platform that can assist the practice of medicine and public health with the support of mobile devices [19-21]. Several studies have demonstrated that mHealth technology has improved clinical outcomes in medical patients by improving the control of cardiac function and glycemic hemostasis, enhancing medication compliance, and shortening hospital stay [22-25]. Although the experience of using the mHealth app in surgical care is limited [26,27], it is suggested that surgical patients can benefit from this new technology support and restore the critical decline in physical and medical functions. The mHealth system and its associated mobile apps support many theory-based techniques that have shown to increase PA in behavioral interventions [28-31], with self-monitoring being the most important element associated with success of the intervention [29]. With the support of technology-based trackers, patients are encouraged to self-monitor, and wearing automatic recorders of PA reduces the burden. Furthermore, 1 study investigated the accuracy in step counting among commercially available wearable devices, showing that most devices did not overcount or undercount steps [32]. These findings are particularly important for clinical interventions using such wearable devices for clinical research.

\section{Objectives}

Five years ago, our team worked with bioinformatics developers at our university to create a new first-generation mobile phone/tablet app (SurgeryDiary) to accelerate recovery in patients who have undergone gastrointestinal surgery [33]. This next-generation app implemented a wearable device to track daily PA of patients with GC. This pilot study focused on the feasibility and clinical value of the second-generation app in patients with GC. In addition, this study determined the correlation between PA variables collected from the wearable device and outcomes and illustrated how the device can be used to estimate patient recovery.

\section{Methods}

\section{Study Population}

In this study, eligible participants were adult inpatients (aged $\geq 20$ years) on the general surgery service of an academic teaching hospital. We enrolled patients who were undergoing laparoscopic or open gastrectomy for GC at our institution from January 2016 to December 2017. All patients fulfilling the inclusion criteria were approached to participate in this study. Notably, patients were excluded if they had preoperative walking disorders (paralysis or hemiplegia) or prolonged stay in the intensive care unit (ICU). During the study period, 50 patients were screened; of these patients, we enrolled 43 in this study, excluding 7 with a prolonged ICU stay. This study protocol was approved by the institutional review board of the National Taiwan University Hospital (201412040RIND). A research assistant helped the enrolled patients to install the app on their smartphones and instructed them on how to use the app preoperatively. Before the enrollment of this study, the research assistant would evaluate the patients' familiarity with wearable devices and smartphones. If the patients were not confident about using these devices, we would provide further instruction to their caregivers. 
Data of patients' demographics and oncological factors were obtained by 2 medical professionals after reviewing charts (discharge summaries, imaging reports, and pathological reports). Regarding comorbidities, we collected the following data on the comorbidity of patients before gastrectomy using the International Classification of Diseases, 9th Revision, Clinical Modification (ICD-9-CM) codes: anemia (ICD-9-CM: 285.x), myocardial infarction (410.x and 412.x), mild liver disease (571.2 and 571.4-571.6), hyperlipidemia (272.0-272.2), diabetes mellitus (250.0-250.3 and 250.7), chronic obstructive pulmonary disease (490.x-496.x), renal failure (584.x-586.x), and hypertension (401.x-405.x). Next, we used the Charlson comorbidity index to calculate baseline comorbidity scores for each patient [34]. This was used to compare the baseline comorbidity between the 2 groups. Moreover, we used the Eastern Cooperative Oncology Group performance status to represent the baseline daily living ability [35]. Higher scores in both scales implied that the patients had poor medical and physical functions. Furthermore, the American Society of Anesthesiologists (ASA) score, which ranges from 1 to 5, assesses the preoperative physical status of patients [36]. The definition of ASA 1, 2, 3, 4, and 5 is "a normal healthy patient," "a patient with mild systemic disease," "a patient with severe systemic disease," "a patient with severe systemic disease that is a constant threat to life," and "a moribund patient who is not expected to survive without the operation," respectively. For the oncological variables, including cancer histology and cancer stage, the American Joint Committee on Cancer staging was implemented to determine cancer stages of this study's population [37]. Satisfaction survey of the wearable device and app was measured using items adapted from a previous study [38], including 5 questions (patient comfort using the wearable device, if the patient would continue to wear the device, if it was convenient for the patient to use the app, if the app was user friendly, and if the patient would recommend this app).
All responses were made on a Likert-type scale from 1 (strongly disagree) to 5 (strongly agree) as the study period was completed.

\section{The App}

SurgeryDiary is an iOS/Android app that facilitates patients who have undergone gastrectomy to access educational information of surgical procedures, record perioperative clinical variables (PA, associated discomfort, body weight, and drain amount), and transmit digital images of the surgical wound to the medical staff. PA (Figure 1, left) and heart rate (Figure 1, right) could be graphed for diverse study periods (ranging from days to years), and patients/caregivers could view the change in PA or heart rate by time increment. This app was developed by surgical professionals and software programmers to fulfill the need of the patients. The wearable device for recording PA (number of steps) is Apple Watch for iOS and Samsung Gear S2 for Android. Reportedly, both devices could reliably measure the number of steps as effective health evaluation indicators [39]. Figure 2 presents the system architecture. The wearable devices initially collected daily step count data, which were then transferred to the original customized wearable apps in the smartphones using the sync functionality. Furthermore, our designed app captured the data stored in the original customized wearable app. Next, data in our designed app were sent to the server when internet access was available for these smartphones. This function of interdevice data transmission worked well with no abnormal events reported by the patients. Furthermore, 1 case manager monitored the synchronous data during daytime on weekdays and would call the patients if their step counts had decreased or were completely missed. Patients continued to transmit data until postoperative day 28 , and 1 medical staff who did not participate in designing this system independently reviewed and analyzed data. 
Figure 1. Screenshots of the app showing the number of walking steps (left) and heart rates (right) at different periods.
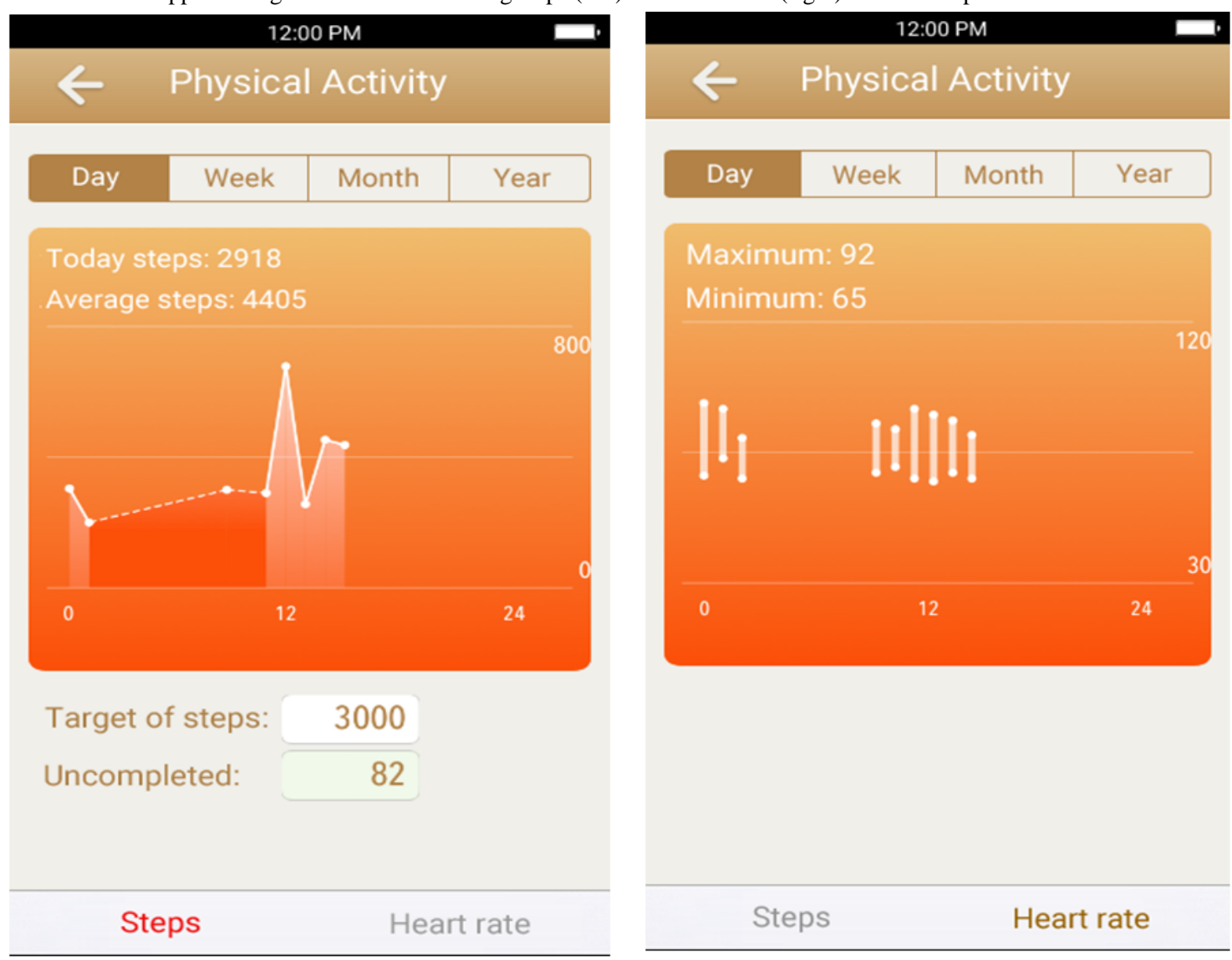

Figure 2. The system architecture: the wearable device for recording physical activity (number of steps) is Apple Watch for iOS and Samsung Gear $\mathrm{S} 2$ for Android. The wearable devices connected and sent data to the original customized apps in mobile phones, which were further connected to our designed app. SQL: standard database language.

\section{Telemonitoring platform}

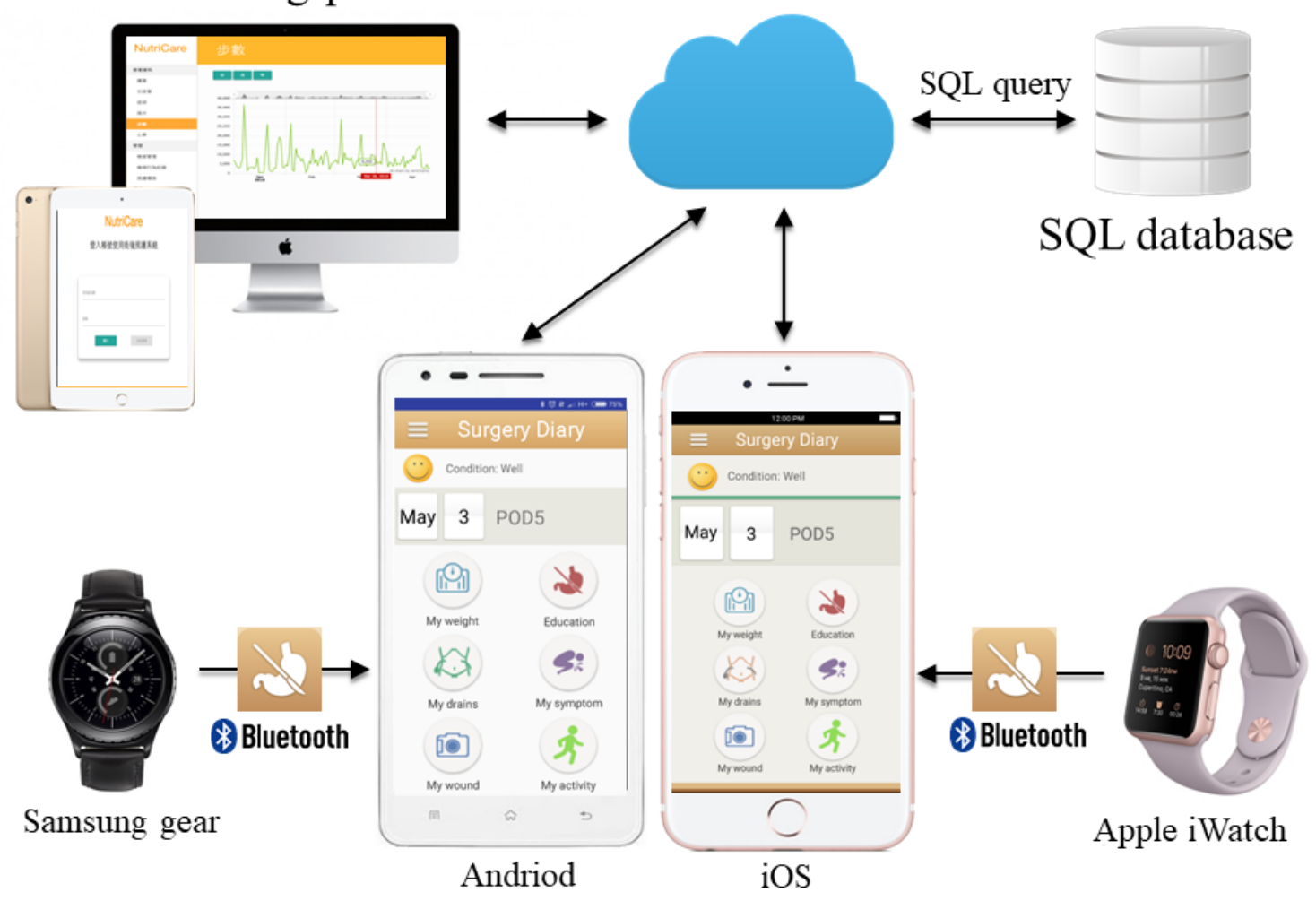




\section{Outcomes}

\section{Feasibility: Protocol Completion}

In this study, feasibility was defined as the proportion of participants using each element of the system (wearable device and uploading step counts) for at least $70 \%$ of the 28-day study period [40]. "Definitely feasible," "possibly feasible," and "not feasible" were defined as $\geq 70 \%, 50 \%-69 \%$, and $<50 \%$ participants meeting criteria, respectively.

\section{Clinical Value: Association of Walking Steps and Early Discharge}

The outcome of clinical value was to validate whether the improvement of PA based on wearable devices was a reliable parameter to estimate early discharge (length of hospital stay $<9$ days) in patients who had undergone gastrectomy. Our hypothesis was based on 1 report addressing that physical functional recovery, including adequate pain control, ability to mobilize, tolerance of oral intake, and no abnormal physical findings or laboratory tests, could be achieved on postoperative day 5 in patients with GC who had undergone gastrectomy; this was a parameter to predict if patients would qualify for early discharge [41]. Furthermore, we collected demographic (age, gender, body mass index, and comorbidities), type of gastrectomy, minimal invasive surgery, cancer histology, and cancer stage information for statistical adjustment.

\section{Results}

\section{Participants' Characteristics}

Of the 43 analyzed patients (Table 1), 51\% (22/43) were males, and the median age was 68 years, which is consistent with that observed in the population with GC in Taiwan. The median age of male and female patients was 72 years and 59 years, respectively. Among the study population, the median body weight was $65 \mathrm{~kg}$ and the median body mass index was 22.3. Regarding surgical procedures, there were 7 (16\%) wedge resections, $30(70 \%)$ subtotal gastrectomies, and $6(14 \%)$ total gastrectomies. We observed a low value of serum albumin $(<4.0$ $\mathrm{mg} / \mathrm{dl}$; parameter of malnutrition) in $15(35 \%)$ patients, and 22 (51\%) patients had an ASA physical status classification system score of $>2$. Notably, 30 patients $(70 \%)$ depended on the assistance of active caregivers to perform this task because of old age or limited prior experience with technology.

All questions received a mean rating over 4 out of 5 , but $2(5 \%)$ patients reported a rating of 3 for 1 question ("patient comfort using the wearable device").

\section{Feasibility: Protocol Completion}

All participants submitted step data every day in the first week. The weekly submission rate in the second, third, and fourth week was $93 \%, 91 \%$, and $86 \%$, respectively. The overall daily submission rate was $95.5 \%$ (1150 of days, given 43 subjects submitting data for 28 days). Of 54 missed transmission days, 6 occurred in the second week, 12 occurred in the third week, and 36 occurred in the fourth week. The leading reason for not sending data was that patients/caregivers forgot to charge the wearable devices $(>90 \%)$.

\section{Clinical Value: Association of Walking Steps and Early Discharge}

Table 2 outlines the comparison of study subjects with early discharge and without early discharge. There were 19 (44\%) patients with early discharge. The patients with early discharge exhibited a significantly higher proportion of patients with minimal invasive surgery $(68 \%$ vs $29 \% ; P=.01)$, cancer histology of gastrointestinal stromal cancer ( $32 \%$ vs $4 \% ; P=.01)$, and more walking steps on postoperative day 5 (5823 vs 4311; $P=.01)$ compared with the patients without early discharge. Furthermore, we validated whether walking steps could predict early discharge using the logistic regression model (Table 3 ). We included significant variables on univariable analysis with a $P<.05$ into the multivariable analysis, which demonstrated that every 1000-step increment of walking on postoperative day 5 was associated with early discharge (odds ratio $2.72,95 \%$ CI $1.17-6.32 ; P=.019$ ) after adjustment of both baseline physical status and aforementioned variables. 
Table 1. Demographic characteristics of study subjects, participant adherence to the protocol, and clinical outcomes.

\begin{tabular}{ll}
\hline Characteristic & Data $(\mathrm{N}=43)$ \\
\hline Age, median $\left(\mathrm{IQR}^{\mathrm{a}}\right)$ & $68.0(58.0-75.0)$ \\
Male, $\mathrm{n}(\%)$ & $22(51)$ \\
Body mass index, median (IQR) & $22.3(19.9-25.8)$ \\
Value of serum albumin (mg/dl) $<4, \mathrm{n}(\%)$ & $15(35)$ \\
Smoking history, $\mathrm{n}(\%)$ & $39(91)$ \\
American Society of Anesthesiologists score $>2, \mathrm{n}(\%)$ & $22(51)$ \\
Minimal invasive surgery, $\mathrm{n}(\%)$ & $20(47)$ \\
Charlson Comorbidity Index $>2, \mathrm{n}(\%)$ & $10(23)$
\end{tabular}

\section{Education level, $\mathbf{n}(\%)$}

Illiterate

Up to high school

$>$ High school

Employment level, n (\%)

Full-time employment

Part-time employment

Retired

Unemployed

Financial situation, $\mathbf{n}(\%)$

Self-pay

Social support

Place of residence, $n(\%)$

Urban area

Rural area

$13(30)$

Eastern Cooperative Oncology Group performance status scales, n (\%)

0

1

Method of gastrectomy, n (\%)

Wedge resection

Subtotal gastrectomy

Total gastrectomy

Histological classification, $\mathrm{n}(\%)$

Adenocarcinoma

Malignant gastrointestinal stromal tumor

System of American Joint Committee on Cancer staging, $\mathbf{n}(\%)$

Stage I

Stage II

Stage III

Major complication

Method of participation, $n(\%)$

Caregiver

Independent

$30(70)$

App system, n (\%) 


\begin{tabular}{ll}
\hline Characteristic & Data (N=43) \\
\hline Android & $38(88)$ \\
iOS & $5(12)$ \\
Participant compliance, $\mathbf{n}(\%)$ & \\
At first week & $43(100)$ \\
At second week & $40(93)$ \\
At third week & $39(91)$ \\
At fourth week & $37(86)$ \\
Overall daily compliance & 1204 \\
Total submissions (person-day) & $1150(95)$ \\
Days submitted, $n(\%)$ & $54(5)$ \\
Days missed, n (\%) & \\
\hline
\end{tabular}

${ }^{\mathrm{a}} \mathrm{IQR}$ : interquartile range.

Table 2. Comparison of the study subjects with early discharge and without early discharge.

\begin{tabular}{|c|c|c|c|}
\hline Characteristic & $\begin{array}{l}\text { Without early discharge } \\
(\mathrm{n}=24)\end{array}$ & $\begin{array}{l}\text { With early discharge } \\
(\mathrm{n}=19)\end{array}$ & $P$ value \\
\hline Age, median $\left(\mathrm{IQR}^{\mathrm{a}}\right)$ & $68.0(58.5-74.5)$ & $66.0(56.0-77.0)$ & .84 \\
\hline Gender (male:female) & $9: 15$ & $12: 7$ & .09 \\
\hline Body mass index, median (IQR) & $22.3(20.9-23.6)$ & $21.7(19.8-28.1)$ & .90 \\
\hline Smoking history, $\mathrm{n}(\%)$ & $21(88)$ & $18(95)$ & .42 \\
\hline Value of serum albumin $(\mathrm{mg} / \mathrm{dl})<4, \mathrm{n}(\%)$ & $10(42)$ & $5(26)$ & .29 \\
\hline American Society of Anesthesiologists score $>2, \mathrm{n}(\%)$ & $14(58)$ & $8(42)$ & .29 \\
\hline Charlson Comorbidity Index $>2, \mathrm{n}(\%)$ & $4(17)$ & $6(32)$ & .25 \\
\hline Eastern Cooperative Oncology Group performance status scales, n (\%) & & & .67 \\
\hline 0 & $21(88)$ & $17(90)$ & $-\mathrm{b}$ \\
\hline 1 & $3(12)$ & $2(10)$ & - \\
\hline Minimal invasive surgery, $\mathrm{n}(\%)$ & $7(29)$ & $13(68)$ & .01 \\
\hline Method of gastrectomy, n (\%) & & & .05 \\
\hline Wedge resection & $1(4)$ & $6(32)$ & - \\
\hline Subtotal gastrectomy & $19(79)$ & $11(58)$ & - \\
\hline Total gastrectomy & $4(17)$ & $2(11)$ & - \\
\hline Cancer histology, n (\%) & & & .01 \\
\hline Adenocarcinoma & $23(96)$ & $13(68)$ & - \\
\hline Gastrointestinal stromal cancer & $1(4)$ & $6(32)$ & - \\
\hline Method of participation, $n(\%)$ & & & .40 \\
\hline Caregiver & $6(25)$ & $7(37)$ & - \\
\hline Independent & $18(75)$ & $12(63)$ & - \\
\hline Walking steps (X1000) on postoperative day 5 , median (IQR) & $4.3(4.1-4.7)$ & $5.8(4.5-6.1)$ & .01 \\
\hline
\end{tabular}

${ }^{\mathrm{a}} \mathrm{IQR}$ : interquartile range.

${ }^{\mathrm{b}}$ Not applicable. 
Table 3. Adjusted multivariate analysis to predict early discharge.

\begin{tabular}{llc}
\hline Characteristic & Odds ratio $(95 \%$ CI) & $P$ value \\
\hline Every 1000-step increment of walking & $2.72(1.17-6.32)$ & .02 \\
Minimal invasive surgery & $4.14(0.71-24.03)$ \\
Method of gastrectomy (reference: wedge resection) & $0.40(0.03-5.36)$ \\
$\quad$ Subtotal gastrectomy & $0.42(0.01-13.26)$ & .11 \\
$\quad$ Total gastrectomy & .63 \\
Cancer pathology (reference: adenocarcinoma) & $1.03(0.71-3.17)$ \\
$\quad$ Gastrointestinal stromal cancer & $0.58(0.12-2.67)$ \\
$\quad$ Eastern Cooperative Oncology Group performance status scales (reference: 0$)$ & .99 \\
\hline
\end{tabular}

\section{Discussion}

\section{Principal Findings}

This study demonstrated the feasibility of using a mobile app connected to a wearable device to record perioperative numbers of steps in patients after major gastrectomy for GC. The PA variable based on the number of steps is a reliable parameter for predicting early discharge from the hospital. To the best of our knowledge, this is one of the innovative studies focusing on the development of comprehensive app functions to track the PA of cancer subjects [42], and we focus on the cancer patients undergoing gastrectomy. This system continues to monitor PA during the crucial perioperative period when several complications and functional/physical disorders occur and result in delayed recovery.

From our results, improved PA was associated with early discharge of the GC patients undergoing gastrectomy. It was because the patients with improved PA had resumed physical function, which was the main factor to evaluate if the patients were qualified to be discharged. One study investigating factors associated with early discharge of patients with GC undergoing gastrectomy found that several factors, such as improved PA, laboratory variables, minimally invasive surgery, and body temperature, could predict early discharge [43]. For the patients undergoing surgical procedures other than gastrectomy, the reports also supported the relationship between improved PA and early discharge $[44,45]$. Our study suggested that the surgical staff should regard PA as an important clinical parameter, which has previously been long ignored as research is often hindered by the challenge of adapting an easy, valid, and reliable measure to record PA [6]. However, because of the relatively small sample, the results of the statistical tests should be interpreted with care; more patients should be enrolled to validate the relationship between improved PA and early discharge.

Although medical professionals acknowledge the significance of PA in the prevention of GC and maintenance of chronic diseases $[3,46]$, few incorporate PA counseling into routine clinic visits/care [47]. The gap between knowledge and implementation of PA in daily practice can be attributed to several reasons, including transitions of care from an inpatient stay to the community, labor of self-recording, and difficult access for medical professionals to check data. The ability to wirelessly interface with wearable and mobile devices and the application of platforms/apps provide surgical patients with a method to share health information with their surgeons. Our app is unique in the breadth and convenience of PA data that it can capture.

In contrast to the rapid growth of the field of medical mHealth, research on surgical subjects who are in much need of continuous care because of a marked decline in general conditions is limited. Among surgical mHealth, the application of wound care is the main topic for validating its clinical effect [48-50] because wound care is a unique issue for surgical patients in comparison with medically ill patients, and telephone conversations or questionnaires cannot be used to access the visual component. In addition to our developed system, a recent study used another wearable device to track step counts of patients who had undergone diverse abdominal surgeries within 1 month after discharge and showed that the mHealth app could effectively track recovery [27]. Both studies established the feasibility of PA generated by wearable devices, which should be routinely implemented in clinical services and daily life to monitor the degree of recovery of surgical patients. However, our system monitored the step counts specifically in patients who had undergone gastrectomy immediately after gastrectomy, which provided more detailed perioperative data of PA for further analysis. In this study, we developed an app that is compatible with both Android and iOS devices to enable its use with any type of mobile devices. Another strength of our study is the largest cases series addressing the use of mHealth app in the GC patients to date.

Several studies have used electronic assessment of patient-report outcomes, which has proved to be as accurate as paper and pencil administration in 1 multicenter observational cohort study $[51,52]$. By collecting information that was unavailable and data that were unavailable in the traditional process of perioperative care, both health care organizations and medical staff can undertake quality improvement initiatives and conduct a comprehensive analysis. Conversely, health care workers in Taiwan are exposed to high levels of occupational stress and heavy workloads [53]. Although PA is a reliable predictor of outcomes for surgical patients, collection of data and records can be another burden for health care workers. At our hospital, we have considered implementing our electronic PA system with the health information system in the future, to attenuate workloads of the medical staff and expedite data extraction and analysis. 


\section{Limitations}

This study should be evaluated in the context of some limitations. First, this study was conducted in a single medical center. The findings of this study might be specific to our subjects, but they warrant additional research in other populations. Thus, we will design a prospective randomized clinical trial to validate the efficacy of this app in patients with GC who are undergoing gastrectomy (a study group treated by wearable devices connected to the research program and a control group treated by wearable devices who are not affiliated with the research program). Second, $4.5 \%$ of patient days exhibited a technological problem that hindered data collection mostly because of the issue of forgetting to charge the battery of the wearable devices. Usually, patients needed to charge the battery every 2 to 3 days, depending on which wearable device they used; in future, devices should be improved, particularly for their battery capacity. Third, a connection between this app and other types of wearable devices was the main barrier that limited the number of participants. Currently, we provided a wearable device to patients, but continuous modification of the system is essential with upgrades of the software and associated devices, including smartphones and wearable devices. Finally, in our study, the metric for PA is daily step count. Moderate to vigorous PA (MVPA) is also an important parameter for assessing PA in surgical patients in conjunction with daily step counts. However, MVPA is relatively more stressful for early postoperative patients compared with simple measures of daily step counts. In future studies, we will validate the role of MVPA on late postoperative surgical patients as they recover to competent physical and mental functions.

\section{Conclusions}

The use of mobile apps implementing wearable devices for recording PA in patients with postoperative $\mathrm{GC}$ was feasible in patients undergoing gastrectomy in this study. With the support of the mHealth platform, this app offers seamless tracing of patients' recovery with a little extra burden and turns subjective PA into an objective, measurable parameter.

\section{Acknowledgments}

The authors would like to thank all members of the Department of Surgery at the National Taiwan University Hospital for their efforts and contribution. This study was supported by grants (Numbers 104-2218-E-002-028 and 106-2628-E-002-004-MY3) from the Ministry of Science and Technology, Taiwan, which had no role in study design, data collection and analysis, decision to publish, or preparation of the manuscript.

\section{Conflicts of Interest}

None declared.

\section{References}

1. Macfarlane DJ, Lee CC, Ho EY, Chan KL, Chan D. Convergent validity of six methods to assess physical activity in daily life. J Appl Physiol (1985) 2006 Nov;101(5):1328-1334 [FREE Full text] [doi: 10.1152/japplphysiol.00336.2006] [Medline: 16825525]

2. Lee IM, Hsieh CC, Paffenbarger Jr RS. Exercise intensity and longevity in men. The Harvard Alumni Health Study. J Am Med Assoc 1995 Apr 19;273(15):1179-1184. [doi: 10.1001/jama.1995.03520390039030] [Medline: 7707624 ]

3. Abioye AI, Odesanya MO, Abioye AI, Ibrahim NA. Physical activity and risk of gastric cancer: a meta-analysis of observational studies. Br J Sports Med 2015 Feb;49(4):224-229. [doi: 10.1136/bjsports-2013-092778] [Medline: 24434186]

4. Lahart IM, Metsios GS, Nevill AM, Carmichael AR. Physical activity levels in women attending breast screening, receiving chemotherapy and post-breast cancer treatment; a cross-sectional study. Int J Environ Res Public Health 2014 May 20;11(5):5487-5496 [FREE Full text] [doi: 10.3390/ijerph110505487] [Medline: 24852599]

5. Westerterp KR. Assessment of physical activity: a critical appraisal. Eur J Appl Physiol 2009 Apr;105(6):823-828. [doi: 10.1007/s00421-009-1000-2] [Medline: 19205725]

6. Sylvia LG, Bernstein EE, Hubbard JL, Keating L, Anderson EJ. Practical guide to measuring physical activity. J Acad Nutr Diet 2014 Feb;114(2):199-208 [FREE Full text] [doi: 10.1016/j.jand.2013.09.018] [Medline: 24290836]

7. Ferlay J, Shin HR, Bray F, Forman D, Mathers C, Parkin DM. Estimates of worldwide burden of cancer in 2008: GLOBOCAN 2008. Int J Cancer 2010 Dec 15;127(12):2893-2917 [FREE Full text] [doi: 10.1002/ijc.25516] [Medline: 21351269]

8. Munene G, Francis W, Garland SN, Pelletier G, Mack LA, Bathe OF. The quality of life trajectory of resected gastric cancer. J Surg Oncol 2012 Mar 15;105(4):337-341. [doi: 10.1002/jso.22139] [Medline: 22095440]

9. Crew KD, Neugut AI. Epidemiology of gastric cancer. World J Gastroenterol 2006 Jan 21;12(3):354-362 [FREE Full text] [Medline: 16489633]

10. Price TJ, Shapiro JD, Segelov E, Karapetis CS, Pavlakis N, Van Cutsem E, et al. Management of advanced gastric cancer. Expert Rev Gastroenterol Hepatol 2012 Apr;6(2):199-208. [doi: 10.1586/egh.11.103] [Medline: 22375525]

11. O'Neill L, Moran J, Guinan EM, Reynolds JV, Hussey J. Physical decline and its implications in the management of oesophageal and gastric cancer: a systematic review. J Cancer Surviv 2018 Aug;12(4):601-618. [doi: 10.1007/s11764-018-0696-6] [Medline: 29796931] 
12. Brenkman HJ, Tegels JJ, Ruurda JP, Luyer MD, Kouwenhoven EA, Draaisma WA, LOGICA Study Group. Factors influencing health-related quality of life after gastrectomy for cancer. Gastric Cancer 2018 May;21(3):524-532 [FREE Full text] [doi: 10.1007/s10120-017-0771-0] [Medline: 29067597]

13. Yu W, Park KB, Chung HY, Kwon OK, Lee SS. Chronological changes of quality of life in long-term survivors after gastrectomy for gastric cancer. Cancer Res Treat 2016 Jul;48(3):1030-1036 [FREE Full text] [doi: 10.4143/crt.2015.398] [Medline: 27004956]

14. Campbell NL, Zhan J, Tu W, Weber Z, Ambeuhl R, McKay C, et al. Self-reported medication adherence barriers among ambulatory older adults with mild cognitive impairment. Pharmacotherapy 2016 Feb;36(2):196-202. [doi: 10.1002/phar.1702] [Medline: 26890914]

15. Pettee GK, McClain JJ, Schmid KK, Storti KL, Ainsworth BE. Reliability and convergent validity of the past-week modifiable activity questionnaire. Public Health Nutr 2011 Mar;14(3):435-442. [doi: 10.1017/S1368980010002612] [Medline: 20843404]

16. Jacobs Jr DR, Ainsworth BE, Hartman TJ, Leon AS. A simultaneous evaluation of 10 commonly used physical activity questionnaires. Med Sci Sports Exerc 1993 Jan;25(1):81-91. [Medline: 8423759]

17. Shephard RJ. Limits to the measurement of habitual physical activity by questionnaires. Br J Sports Med 2003 Jun;37(3):197-206 [FREE Full text] [Medline: 12782543]

18. Wildenbos GA, Peute L, Jaspers M. Aging barriers influencing mobile health usability for older adults: a literature based framework (MOLD-US). Int J Med Inform 2018 Jun;114:66-75. [doi: 10.1016/j.ijmedinf.2018.03.012] [Medline: 29673606]

19. Fiordelli M, Diviani N, Schulz PJ. Mapping mHealth research: a decade of evolution. J Med Internet Res 2013;15(5):e95 [FREE Full text] [doi: 10.2196/jmir.2430] [Medline: 23697600]

20. Wayne N, Ritvo P. Smartphone-enabled health coach intervention for people with diabetes from a modest socioeconomic strata community: single-arm longitudinal feasibility study. J Med Internet Res 2014 Jun;16(6):e149 [FREE Full text] [doi: 10.2196/jmir.3180] [Medline: 24907918]

21. Kim BY, Lee J. Smart devices for older adults managing chronic disease: a scoping review. JMIR Mhealth Uhealth 2017 May 23;5(5):e69. [doi: 10.2196/mhealth.7141] [Medline: 28536089]

22. Hung CS, Yu JY, Lin YH, Chen YH, Huang CC, Lee JK, et al. Mortality benefit of a fourth-generation synchronous telehealth program for the management of chronic cardiovascular disease: a longitudinal study. J Med Internet Res 2016 May 13;18(5):e102 [FREE Full text] [doi: 10.2196/jmir.5718] [Medline: 27177497]

23. Doocy S, Paik KE, Lyles E, Hei TH, Fahed Z, Winkler E, et al. Guidelines and mHealth to improve quality of hypertension and type 2 diabetes care for vulnerable populations in Lebanon: longitudinal cohort study. JMIR Mhealth Uhealth 2017 Oct 18;5(10):e158 [FREE Full text] [doi: 10.2196/mhealth.7745] [Medline: 29046266]

24. Ahmed I, Ahmad NS, Ali S, Ali S, George A, Saleem DH, et al. Medication adherence apps: review and content analysis. JMIR Mhealth Uhealth 2018 Mar 16;6(3):e62 [FREE Full text] [doi: 10.2196/mhealth.6432] [Medline: 29549075]

25. Machado SM, Wilson EH, Elliott JO, Jordan K. Impact of a telemedicine eICU cart on sepsis management in a community hospital emergency department. J Telemed Telecare 2018 Apr;24(3):202-208. [doi: 10.1177/1357633X17691862] [Medline: 29278979]

26. Gustavell T, Langius-Eklöf A, Wengström Y, Segersvärd R, Sundberg K. Development and feasibility of an interactive smartphone app for early assessment and management of symptoms following pancreaticoduodenectomy. Cancer Nurs 2018 Mar 27 (forthcoming). [doi: 10.1097/NCC.0000000000000584] [Medline: 29596113]

27. Symer MM, Abelson JS, Milsom J, McClure B, Yeo HL. A mobile health application to track patients after gastrointestinal surgery: results from a pilot study. J Gastrointest Surg 2017 Sep;21(9):1500-1505. [doi: 10.1007/s11605-017-3482-2] [Medline: 28685388]

28. Hartman SJ, Nelson SH, Weiner LS. Patterns of Fitbit use and activity levels throughout a physical activity intervention: exploratory analysis from a randomized controlled trial. JMIR Mhealth Uhealth 2018 Feb 05;6(2):e29 [FREE Full text] [doi: 10.2196/mhealth.8503] [Medline: 29402761]

29. Michie S, Abraham C, Whittington C, McAteer J, Gupta S. Effective techniques in healthy eating and physical activity interventions: a meta-regression. Health Psychol 2009 Nov;28(6):690-701. [doi: 10.1037/a0016136] [Medline: 19916637]

30. Lyons EJ, Lewis ZH, Mayrsohn BG, Rowland JL. Behavior change techniques implemented in electronic lifestyle activity monitors: a systematic content analysis. J Med Internet Res 2014;16(8):e192 [FREE Full text] [doi: 10.2196/jmir.3469] [Medline: 25131661]

31. Mercer K, Li M, Giangregorio L, Burns C, Grindrod K. Behavior change techniques present in wearable activity trackers: a critical analysis. JMIR Mhealth Uhealth 2016;4(2):e40 [FREE Full text] [doi: 10.2196/mhealth.4461] [Medline: 27122452]

32. Modave F, Guo Y, Bian J, Gurka MJ, Parish A, Smith MD, et al. Mobile device accuracy for step counting across age groups. JMIR Mhealth Uhealth 2017 Jun 28;5(6):e88 [FREE Full text] [doi: 10.2196/mhealth.7870] [Medline: 28659255]

33. Wu JM, Yu HJ, Ho TW, Su XY, Lin MT, Lai F. Tablet PC-enabled application intervention for patients with gastric cancer undergoing gastrectomy. Comput Methods Programs Biomed 2015 Apr;119(2):101-109. [doi: 10.1016/i.cmpb.2015.03.004] [Medline: 25819034] 
34. Quan H, Li B, Couris CM, Fushimi K, Graham P, Hider P, et al. Updating and validating the Charlson comorbidity index and score for risk adjustment in hospital discharge abstracts using data from 6 countries. Am J Epidemiol 2011 Mar 15;173(6):676-682. [doi: 10.1093/aje/kwq433] [Medline: 21330339]

35. Oken MM, Creech RH, Tormey DC, Horton J, Davis TE, McFadden ET, et al. Toxicity and response criteria of the Eastern Cooperative Oncology Group. Am J Clin Oncol 1982 Dec;5(6):649-655. [Medline: 7165009]

36. Fitz-Henry J. The ASA classification and peri-operative risk. Ann R Coll Surg Engl 2011 Apr;93(3):185-187 [FREE Full text] [doi: 10.1308/rcsann.2011.93.3.185a] [Medline: 21477427]

37. Wang J, Dang P, Raut CP, Pandalai PK, Maduekwe UN, Rattner DW, et al. Comparison of a lymph node ratio-based staging system with the 7th AJCC system for gastric cancer: analysis of 18,043 patients from the SEER database. Ann Surg 2012 Mar;255(3):478-485. [doi: 10.1097/SLA.0b013e31824857e2] [Medline: 22330040]

38. Lyons EJ, Swartz MC, Lewis ZH, Martinez E, Jennings K. Feasibility and acceptability of a wearable technology physical activity intervention with telephone counseling for mid-aged and older adults: a randomized controlled pilot trial. JMIR Mhealth Uhealth 2017 Mar 06;5(3):e28 [FREE Full text] [doi: 10.2196/mhealth.6967] [Medline: 28264796]

39. Xie J, Wen D, Liang L, Jia Y, Gao L, Lei J. Evaluating the validity of current mainstream wearable devices in fitness tracking under various physical activities: comparative study. JMIR Mhealth Uhealth 2018 Apr 12;6(4):e94 [FREE Full text] [doi: 10.2196/mhealth.9754] [Medline: 29650506]

40. Meyer N, Kerz M, Folarin A, Joyce DW, Jackson R, Karr C, et al. Capturing rest-activity profiles in schizophrenia using wearable and mobile technologies: development, implementation, feasibility, and acceptability of a remote monitoring platform. JMIR Mhealth Uhealth 2018 Oct 30;6(10):e188. [doi: 10.2196/mhealth.8292] [Medline: 30377146]

41. Jeong O, Ryu SY, Park YK. Postoperative functional recovery after gastrectomy in patients undergoing enhanced recovery after surgery: a prospective assessment using standard discharge criteria. Medicine (Baltimore) 2016 Apr;95(14):e3140 [FREE Full text] [doi: 10.1097/MD.0000000000003140] [Medline: 27057836]

42. Kiss N, Baguley BJ, Ball K, Daly RM, Fraser SF, Granger CL, et al. Technology-supported self-guided nutrition and physical activity interventions for adults with cancer: systematic review. JMIR Mhealth Uhealth 2019 Feb 12;7(2):e12281 [FREE Full text] [doi: 10.2196/12281] [Medline: 30747720]

43. Park JH, Son YG, Kim TH, Huh YJ, Yang JY, Suh YJ, et al. Identification of candidates for early discharge after gastrectomy. Ann Surg Oncol 2017 Jan;24(1):159-166. [doi: 10.1245/s10434-016-5447-1] [Medline: 27448119]

44. Jones D, Musselman R, Pearsall E, McKenzie M, Huang H, McLeod RS. Ready to go home? Patients' experiences of the discharge process in an enhanced recovery after surgery (ERAS) program for colorectal surgery. J Gastrointest Surg 2017 Nov;21(11):1865-1878. [doi: 10.1007/s11605-017-3573-0] [Medline: 28932946]

45. Rae A. Reasons for delayed patient discharge following day surgery: a literature review. Nurs Stand 2016 Nov 09;31(11):42-51. [doi: 10.7748/ns.2016.e10292] [Medline: 27848403]

46. Hébert ET, Caughy MO, Shuval K. Primary care providers' perceptions of physical activity counselling in a clinical setting: a systematic review. Br J Sports Med 2012 Jul;46(9):625-631. [doi: 10.1136/bjsports-2011-090734] [Medline: 22711796]

47. Diaz KM, Krupka DJ, Chang MJ, Peacock J, Ma Y, Goldsmith J, et al. Fitbit@: an accurate and reliable device for wireless physical activity tracking. Int J Cardiol 2015 Apr 15;185:138-140. [doi: 10.1016/j.ijcard.2015.03.038] [Medline: 25795203]

48. Gunter R, Fernandes-Taylor S, Mahnke A, Awoyinka L, Schroeder C, Wiseman J, et al. Evaluating patient usability of an image-based mobile health platform for postoperative wound monitoring. JMIR Mhealth Uhealth 2016 Sep 28;4(3):e113 [FREE Full text] [doi: 10.2196/mhealth.6023] [Medline: 27683059]

49. Fernandes-Taylor S, Gunter RL, Bennett KM, Awoyinka L, Rahman S, Greenberg CC, et al. Feasibility of implementing a patient-centered postoperative wound monitoring program using smartphone images: a pilot protocol. JMIR Res Protoc 2017 Feb 22;6(2):e26 [FREE Full text] [doi: 10.2196/resprot.6819] [Medline: 28228369]

50. Gunter RL, Fernandes-Taylor S, Rahman S, Awoyinka L, Bennett KM, Weber SM, et al. Feasibility of an image-based mobile health protocol for postoperative wound monitoring. J Am Coll Surg 2018 Mar;226(3):277-286. [doi: 10.1016/j.jamcollsurg.2017.12.013] [Medline: 29366555]

51. Rosner BI, Gottlieb M, Anderson WN. Accuracy of internet-based patient self-report of postdischarge health care utilization and complications following orthopedic procedures: observational cohort study. J Med Internet Res 2018 Jul 20;20(7):e10405 [FREE Full text] [doi: 10.2196/10405] [Medline: 30030212]

52. Coons SJ, Gwaltney CJ, Hays RD, Lundy JJ, Sloan JA, Revicki DA, et al. Recommendations on evidence needed to support measurement equivalence between electronic and paper-based patient-reported outcome (PRO) measures: ISPOR ePRO Good Research Practices Task Force report. Value Health 2009 Jun;12(4):419-429. [doi: 10.1111/j.1524-4733.2008.00470.x] [Medline: 19900250]

53. Tsai YC, Liu CH. Factors and symptoms associated with work stress and health-promoting lifestyles among hospital staff: a pilot study in Taiwan. BMC Health Serv Res 2012 Jul 16;12:199 [FREE Full text] [doi: 10.1186/1472-6963-12-199] [Medline: 22799278]

\section{Abbreviations}

ASA: American Society of Anesthesiologists 
GC: gastric cancer

ICD-9-CM: International Classification of Diseases, 9th Revision, Clinical Modification

ICU: intensive care unit

mHealth: mobile health

MVPA: moderate to vigorous physical activity

PA: physical activity

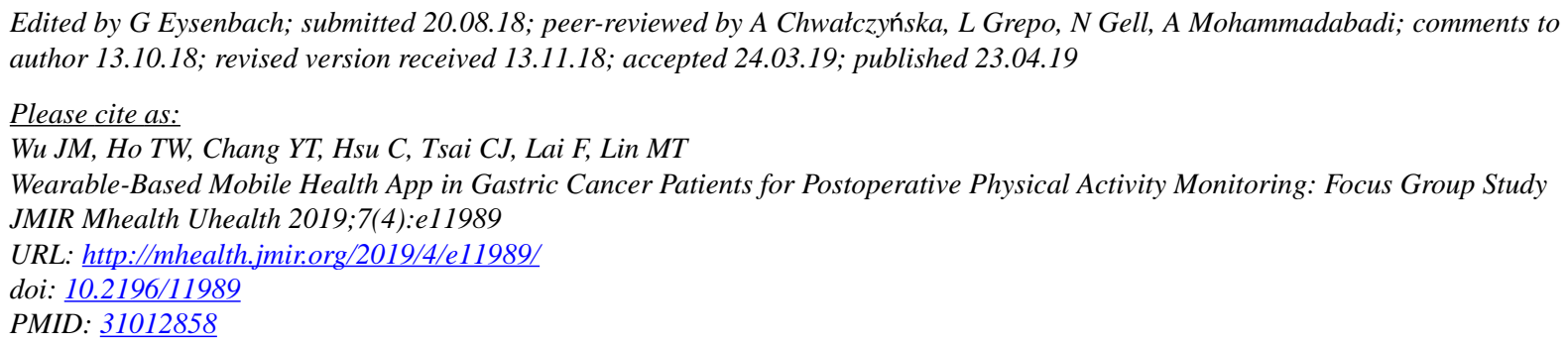

CJin-Ming Wu, Te-Wei Ho, Yao-Ting Chang, ChungChieh Hsu, Chia Jui Tsai, Feipei Lai, Ming-Tsan Lin. Originally published in JMIR Mhealth and Uhealth (http://mhealth.jmir.org), 23.04.2019. This is an open-access article distributed under the terms of the Creative Commons Attribution License (https://creativecommons.org/licenses/by/4.0/), which permits unrestricted use, distribution, and reproduction in any medium, provided the original work, first published in JMIR mhealth and uhealth, is properly cited. The complete bibliographic information, a link to the original publication on http://mhealth.jmir.org/, as well as this copyright and license information must be included. 